\title{
Acrylic Acid Neutralization for Enhancing the Production of Grafted Chitosan Superabsorbent Hydrogel
}

\author{
Dhena Ria Barleany", Retno Sulistyo Dhamar Lestari", Meri Yulvianti", Taufik Rachman Susanto\#, \\ Shalina ${ }^{\#}$, Erizal ${ }^{*}$ \\ \# Department of Chemical Engineering, Universitas Sultan Ageng Tirtayasa, Jln. Jenderal Sudirman Km. 3, Cilegon, 42434, Indonesia \\ E-mail:dbarleany@yahoo.com,retno.sulistyo81@gmail.com,meri_yulvianti@yahoo.com,taufikrachman2707@gmail.com, \\ caca09shalina@gmail.com \\ * Centre for Application of Isotopes and Radiation, Jakarta, Indonesia \\ E-mail:izza3053@yahoo.com
}

\begin{abstract}
Acrylic acid is a hydrophilic monomer which becomes the most popular material used to synthesize superabsorbent polymer. In this recent study, acrylic acid was partially neutralized with $\mathrm{KOH}$ and mixed with chitosan to form a superabsorbent hydrogel poly (acrylic acid) - graft - chitosan by using of gamma ray irradiation technique. The aim of this study was to determine the optimum composition of $\mathrm{KOH}$ in acrylic acid partial neutralization process for enhancing the production of grafted polymer. The degree of neutralization was varied $(0,25,50,75$, and 100$) \%$ and the effect on the superabsorbent characteristics were studied. Hydrogel products were characterized by Fourier Transform Infrared (FTIR) and Scanning Electron Microscopy (SEM). The gel content, swelling ratio, Equilibrium Degree of Swelling (EDS), and Thermal Analysis were also performed. The highest water swelling capacity was 715 (g water/g dry hydrogel), and the gel content was $91.23 \%$, resulted from $75 \%$ of acrylic acid neutralization. The swelling capacity of the products was also tested in urea and $\mathrm{NaCl}$ solutions and reached 750 ( $\mathrm{g}$ urea solution/g dry hydrogel) for urea and 378,33 (g NaCl solution/g dry hydrogel) for $\mathrm{NaCl}$. The huge water absorption capacity indicated that the hydrogel from this research was a superabsorbent product which was suitable for hygiene products application. The degree of neutralization did not show a significant influence on the thermal resistance of the grafted hydrogel produced in this study.
\end{abstract}

Keywords - acrylic acid; chitosan; neutralization; superabsorbent hydrogel

\section{INTRODUCTION}

Hydrogels are polymeric structures held together as water-swollen gels by primary covalent cross-links, ionic forces, hydrogen bonds, affinity or "bio-recognition" interaction, hydrophobic interactions, polymer crystallites, physical entanglements of individual polymer chains, or a combination of two or more interactions. Depending on their method of preparation, ionic charge, or physical structure features, hydrogels may be classified in several categories; they may be homopolymer hydrogels, copolymer hydrogels, multi-polymer hydrogels, and interpenetrating network (IPN) hydrogels [1]. Hydrogels are 3D networks of polymer chains that bring great interest in some applications. A strong repulsive force is generated among those abundant functional groups with the same charge, which enables the hydrogels to be initially applied to the superabsorbent materials [2].

Furthermore, in accordance with the development of technology and the need for new materials that can be applied in the field of health, in recent years hydrogels researched and developed for applications in the biomedical field such as wound dressing [3]-[6] and personal hygiene products (baby diapers and sanitary napkins) [7]-[8]. In water absorbing applications such as baby nappies and adults incontinence pads, superabsorbent hydrogels are ideal due to their ability to absorb and retain large volumes of water and aqueous solutions. Desired features of superabsorbents are high swelling capacity, high swelling rate, and good strength of the swollen gel. Hydrogels produced years ago (conventional hydrogels) have the very low swelling capacity and rate. They mainly need several hours to reach to maximum swelling capacity. In the absorbents incorporated in the baby napkins application, high absorbency and high rate of swelling are very important criteria [9]. Recently, high absorbency and high swelling rate of hydrogels were reported by using different materials and technologies [10]-[11].

Current superabsorbent hydrogels commercially applied in the disposable diapers have disadvantages such as weak 
mechanical strength, poor biocompatibility, and lack of antimicrobial activity, which may include skin allergy of the body. Lack of biocompatibility and biodegradability is the major hassle for the present superabsorbent materials used worldwide as they are made from petroleum-based monomers like acrylic acid and acrylamide [12]. The remedy for this problem is to design the hydrogels by using natural polymers that usually biocompatible and biodegradable, but they have inferior mechanical properties compared to polymers synthesized from petroleum-based materials [13].

Technological science needs innovations in the hydrogel synthesis. One of them is by combining synthetic material with natural material. Many studies conducted to modify polymers with other ingredients to enhance the absorption ability and durability of its physical properties by utilizing natural materials like chitosan. Chitin derivative of chitosan is the most common natural polymer that attracted to be explored in the hydrogel synthesis. Chitosan is a material that has the immense structural possibility for chemical and mechanical modification [14]. Like any other natural materials, chitosan is biocompatible and can be easily degraded [15]. The hydrophilicity of chitosan, due to the presence of amino and hydroxyl functional groups in its repeat unit, makes the polymer soluble in dilute acidic solutions and yield a rubbery hydrogel in water [16]. The abundant hydroxyl and amino groups distributed on its chain, allow chitosan to be modified via chemical reactions, graft copolymerization constituting one such modification for chitosan [17]. Chitosan-based hydrogels have been widely studied for some purposes area and also combined with other natural materials [3], [6], [18], [19] or synthetic materials [20]-[22].

Acrylic acid is a well-known polymer that is usually used to produce superabsorbent hydrogel [23]-[25]. Chitosan grafted poly (acrylic acid) polymers have been reported by some researchers and showed great properties for some fields of applications [26]-[29]. This present study focuses on the effect of acrylic acid neutralization by using of potassium hydroxide to the swelling ability of chitosangrafted polymer.

Covalently cross-linked hydrogels are usually prepared by bringing together small multi-functional molecules such as monomers and oligomers, and reacting to form a network structure. Sometimes large polymer molecules may be crosslinked with the same small multi-functional molecules. Such cross-linking may be achieved by reaction of two chemical groups on two different molecules, which can be initiated by catalysts, by photo-polymerization or by radiation crosslinking [1]. The radiation processing has several advantages such as the simultaneous crosslinking and sterilization in one step and the easy control of physical properties of hydrogels by combining dose with polymer composition; it allows fabricating a pure and human-friendly product noncontaminated with ballast materials or the residuals of toxic initiators [30]. Irradiation technique was successfully reported by some researchers to synthesize superabsorbent hydrogels, some were using gamma-irradiation [24], [25], [30], [31], blue and green LED irradiations [32], microwave irradiation [26], and electron beam irradiation [33]. The aim of this research is to synthesize the superabsorbent hydrogel from chitosan and partially neutralized the acrylic acid by using the gamma-irradiation method.

\section{MATERIAL AND METHOD}

\section{A. Materials}

Acrylic acid 99\% (Merck) was as main material, potassium hydroxide $(\mathrm{KOH})$ for acrylic acid neutralization (Merck), industrial grade of chitosan with deacetylation degree $85 \%, \mathrm{NaCl}$ and Urea (Merck) are used for salt and urea absorption measurements. Swelling measurements were done by using an analytical balance (Scaltec), homogenizer and stirrer (WiseStir HSH-200) for homogenization before irradiation, oven (Heraeus) was for polymer drying process. Synthesis of the superabsorbent polymer was performed by gamma irradiation procedures using irradiators Co60, and the FTIR spectra were recorded on Spectrophotometer Fourier Transform Infrared Shimadzu Prestige-21.

\section{B. Preparation of Chitosan-g-poly (potassium acrylate) Hydrogel}

An amount of $85 \mathrm{~mL}$ of distilled water were put in the container glass beaker $250 \mathrm{~mL}$ and then $15 \mathrm{~mL}$ of partially neutralized acrylic acid with the variation of mol concentration of potassium hydroxide $(0 \%, 25 \%, 50 \%, 75 \%$, and $100 \%$ ) were added to form a solution of potassium acrylate. $0.5 \mathrm{~g}$ of chitosan were then added and homogenized with a stirrer. The solution mixture is packed in a plastic container and then irradiated with gamma rays at a constant dose of $5 \mathrm{kGy}$. Results of irradiation in the form of gel is then removed from the plastic container and dried at $60^{\circ} \mathrm{C}$ for 24 hours. The dried hydrogels were then cut into smaller pieces and ground to form granulated superabsorbent resins.

\section{Equilibrium Degree of Swelling (EDS) Analysis}

EDS shows the hydrogel ability to absorb water at equilibrium condition. A number of $0.1 \mathrm{~g}$ of superabsorbent hydrogel sample were placed in a glass beaker containing $100 \mathrm{~mL}$ of distilled water and allowed to immerse for $24 \mathrm{~h}$. Tests have been carried out by 3 replications. EDS ( $\mathrm{g}$ water/g dry hydrogel) can be calculated using the following equation:

$$
E D S=\frac{W s-W_{0}}{W_{0}}
$$

Where $W_{s}$ is the weight of the hydrogel in a state of optimum swelling after $24 \mathrm{~h}$ of immersion ( $\mathrm{g}$ ) and Wo is the initial weight of the dry hydrogel $(\mathrm{g})$.

\section{Gel Content Analysis}

A weight of $0.01 \mathrm{~g}$ of hydrogel was measured $\left(\mathrm{W}_{0}\right)$, then placed in a tea bag and soaked in $200 \mathrm{~mL}$ of distilled water at room temperature for $24 \mathrm{~h}$. After $24 \mathrm{~h}$, the hydrogel was then dried in a vacuum oven to $60^{\circ} \mathrm{C}$ for $24 \mathrm{~h}$ until a constant weight and then weighed $\left(\mathrm{W}_{\mathrm{g}}\right)$. The gel content $(\%)$ was then calculated by the following equation:

$$
\text { gel content }=\frac{W_{g}-W_{0}}{W_{0}} \times 100 \%
$$

where $\mathrm{W}_{\mathrm{g}}$ is the dry weight of the hydrogel after immersion (g) and $\mathrm{W}_{0}$ is the initial dry weight of the hydrogel before the immersion $(\mathrm{g})$. 


\section{E. Swelling Ratio Study}

In the water swelling ratio analysis, $0.1 \mathrm{~g}$ of hydrogels with varied neutralization of acrylic acid $(0 \%, 25 \%, 50 \%$, $75 \%$, and $100 \%)(\mathrm{n} / \mathrm{n})$ were placed into a glass beaker containing $100 \mathrm{~mL}$ of distilled water then allowed to stand with the time variations of $30,60,90,120,150$, and $180 \mathrm{~s}$. Furthermore, the swollen water hydrogel was filtered, and the water is coming out of the hydrogel is collected in a container and weighed. Water that is absorbed in the hydrogels is calculated from the difference between the initial dry weight and the weight of swollen hydrogel at the time t.

The swelling ratio was also measured in salt and urea solution. $100 \mathrm{mg}$ of dry hydrogel was immersed into varied concentration of $\mathrm{NaCl}$ solution $(0.9 \%, 0.09 \%$, and $0.009 \%)$ (w/v) within $1 \mathrm{~h}$. The same way was used to measure the absorption capacity of the hydrogel in the urea solution. The swelling ratio ( $\mathrm{g}$ water/g dry hydrogel) of 15 minutes time intervals can be calculated by the following expression:

$$
\text { Swelling Ratio }=\frac{W t-W_{0}}{W_{0}}
$$

where $\mathrm{W}_{\mathrm{t}}$ is the weight of the hydrogel in a state of swelling $(\mathrm{g})$ at time $\mathrm{t}$ and $\mathrm{W}_{0}$ is the weight of dry hydrogel $(\mathrm{g})$.

\section{F. FTIR Study}

The powdered hydrogel was mixed with potassium bromide, and then the spectrum of each sample was obtained using Shimadzu IR Prestige-21 spectrometer model 800 series from 4000 to $500 \mathrm{~cm}-1$.

\section{G. DTG}

Thermal degradation of $15 \mathrm{mg}$ sample of hydrogel was measured using a DTA-TG at the range temperature of 30$500^{\circ} \mathrm{C}$

\section{H. SEM}

Superabsorbent hydrogel samples were immersed for $24 \mathrm{~h}$ until the equilibrium and then freeze for $24 \mathrm{~h}$. The samples were freeze-dried at a temperature of $-105^{\circ} \mathrm{C}$ and then coated with a thin layer of gold and analysed using SEM.

\section{RESULTS AND DISCUSSION}

In this study, the hydrogel was synthesized by using $\mathrm{Co}^{60}$ gamma irradiation at a constant dose of $5 \mathrm{kGy}$. This dose was selected based on the previous study [24]. A Higher dose of irradiation caused the increasing of the density of the crosslinked polymer, and as a result, the amount of water absorbed in the hydrogel matrix was decreased [10]. The physical behavior of hydrogels is a dependent on their dynamic swelling and equilibrium in water and in aqueous solutions. Much of the water within swollen hydrogels may be bound to the polymer chains by either polar or hydrophobic interactions [1].

Chitosan is a natural polysaccharide which can be degraded during the irradiation. On the other hand, acrylic acid is well known to be polymerized and crosslinked in an aqueous medium. When a mixture containing acrylic acid and natural polymer (chitosan) is gamma irradiated, the formation of an interpenetrating polymer network (IPN) can be occurred [25].
The physical performance of superabsorbent hydrogel from chitosan and partially neutralized acrylic acid compared to superabsorbent hydrogel produced from chitosan and unneutralized acrylic acid was shown in Fig. 1.

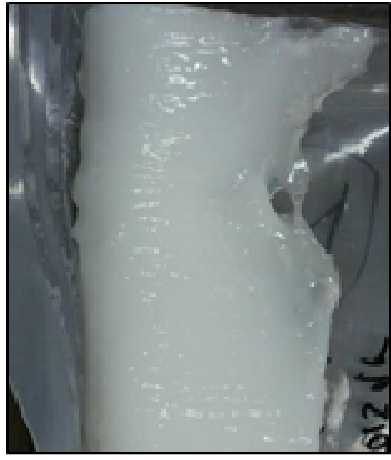

(a)

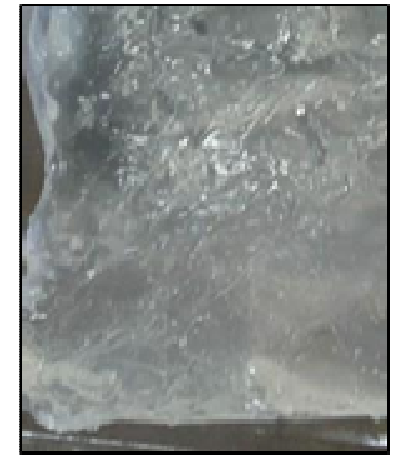

(b)
Fig. 1 Physical performance of the superabsorbent a) Chitosan-g-Poly (potassium acrylate) and (b) Chitosan-g-Poly (acrylic acid)

The photograph proofed that acrylic acid neutralization with potassium hydroxide resulted in the more chewy texture of gel compared with acrylic acid which was not neutralized with potassium hydroxide. When acrylic acid is neutralized with potassium hydroxide then forms potassium acrylate. The colour of chitosan-g-poly (potassium acrylate) was white as milk (Fig. 1a), while chitosan-g-poly (acrylic acid) was slightly brown in colour (Fig. 1b). A hydrogel that has been formed after irradiation was then dried in an oven at $60 \mathrm{oC}$ for $24 \mathrm{~h}$ to eliminate the solvents (Fig. 2a) and then blended to result in powder resin (Fig. 2b).

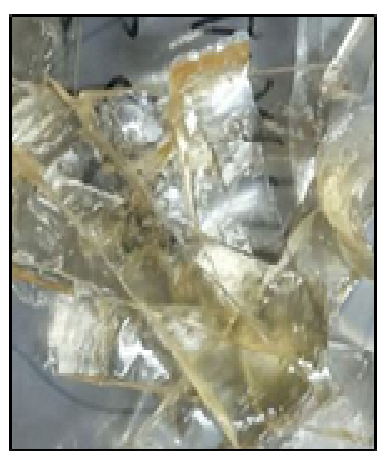

(a)

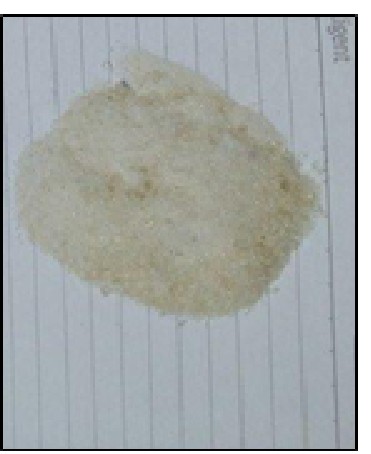

(b)
Fig. 2 Physical performance of (a) dry hydrogel and (b) powder hydrogel.

\section{A. FTIR Study}

Fig. 3c is the IR spectra of acrylic acid which was not irradiated. The functional group of $-\mathrm{O}-\mathrm{H}$ exist at a wavelength of $2500 \mathrm{~cm}-1$, and the group of $\mathrm{C}=\mathrm{C}$ at 1750 $\mathrm{cm}-1$. Fig. $3 \mathrm{~b}$ is the IR spectra of irradiated chitosan, where the group of N-H appeared at a wave number of $3500 \mathrm{~cm}-1$, and a group of $-\mathrm{O}-\mathrm{H}$ at $2500 \mathrm{~cm}-1$. Fig. 3a shows the spectra of acrylic acid which was $50 \%$ partially neutralized with potassium hydroxide grafted onto chitosan. The band at 3500 $\mathrm{cm}-1$ can be attributed to $\mathrm{NH}$ group, the band at $2500 \mathrm{~cm}-1$ attributed to $-\mathrm{OH}$ or $-\mathrm{OK}$ of salt acrylate, and at $1350 \mathrm{~cm}-1$ shows the existing of $\mathrm{CH}$ functional group [34]. The peak at $1750 \mathrm{~cm}-1$ (cluster $\mathrm{H} 2 \mathrm{C}=\mathrm{CH} 2$ ) did not appear in the spectra of chitosan-g-poly (potassium acrylate). This fact indicates that chitosan and neutralized acrylic acid was successfully crosslinked. 


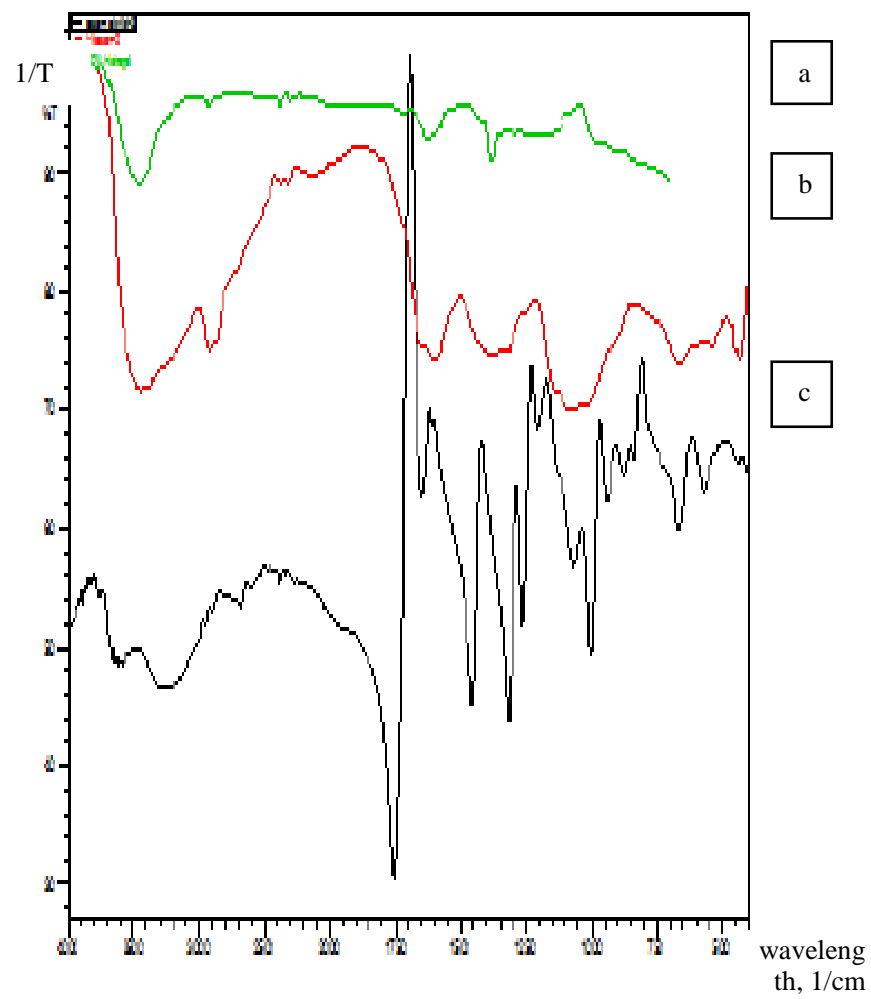

Fig. 3 FTIR Spectra of (a) chitosan-g-poly(potassium acrylate) (b) chitosan and (c) acrylic acid

Fig. 3c is the IR spectra of acrylic acid which was not irradiated. The functional group of $-\mathrm{O}-\mathrm{H}$ exist at a wavelength of $2500 \mathrm{~cm}^{-1}$, and the group of $\mathrm{C}=\mathrm{C}$ at 1750 $\mathrm{cm}^{-1}$. Fig. $3 \mathrm{~b}$ is the IR spectra of irradiated chitosan, where the group of N-H appeared at a wave number of $3500 \mathrm{~cm}^{-1}$, and a group of $-\mathrm{O}-\mathrm{H}$ at $2500 \mathrm{~cm}^{-1}$. Fig. 3a shows the spectra of acrylic acid which was $50 \%$ partially neutralized with potassium hydroxide grafted onto chitosan. The band at 3500 $\mathrm{cm}^{-1}$ can be attributed to $\mathrm{NH}$ group, the band at $2500 \mathrm{~cm}^{-1}$ attributed to $-\mathrm{OH}$ or $-\mathrm{OK}$ of salt acrylate, and at $1350 \mathrm{~cm}^{-1}$ shows the existing of $\mathrm{CH}$ functional group [34]. The peak at $1750 \mathrm{~cm}^{-1}$ (cluster $\mathrm{H} 2 \mathrm{C}=\mathrm{CH} 2$ ) did not appear in the spectra of chitosan-g-poly (potassium acrylate). This fact indicates that chitosan and neutralized acrylic acid was successfully crosslinked.

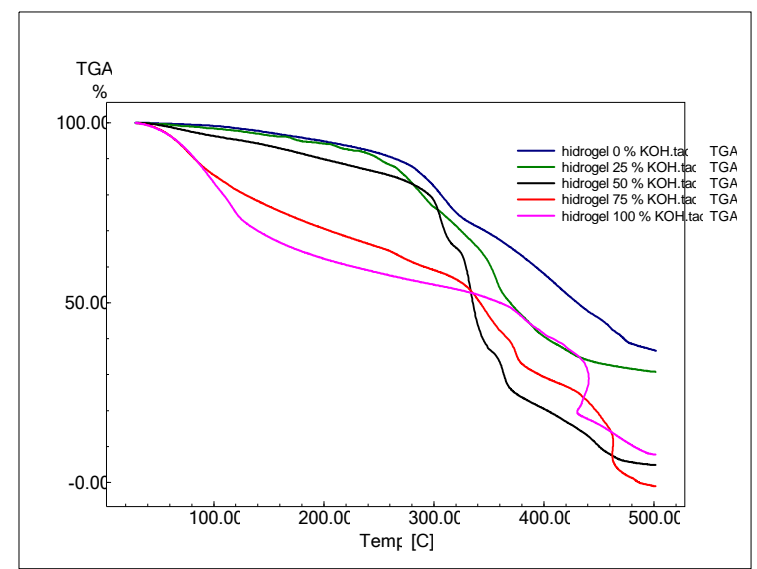

Fig. 4 TGA test for hydrogel with the variation of mol concentration of $\mathrm{KOH} 0 \%, 25 \%, 50 \%, 75 \%$ and $100 \%$

\section{B. DTG Study}

Thermal gravimetric analysis at a temperature range of 29 to $500^{\circ} \mathrm{C}$ was done by using a tool called DTG-60 Simultaneous DTA-TG Apparatus. From the test resulted in Fig. 4, hydrogel with $0 \% \mathrm{~mol}$ of potassium hydroxide degraded through one stage, shown by one peak in the thermogram. For $75 \mathrm{~mol} \%$ of potassium hydroxide composition resulted in two stages of degradation, shown by the appearance of two peaks which indicates an imperfect reaction. The effect of temperature on the amount of degraded hydrogel can also be seen from Fig. 4. Hydrogel with $0 \%, 25 \%, 50 \%, 75 \%$, and $100 \%$ degree of neutralization was degraded $60 \%, 65 \%, 5 \%, 0 \%$, and $10 \%$ (w/w). The higher degree of neutralization causes the higher value of the hydrogel melting point.

\section{Swelling Study}

Fig. 5 shows that swelling ratio increases with the longer time of immersion due to the increasing number of $\mathrm{H}+$ and $\mathrm{OH}$ - ions that bind to the hydrophilic group of hydrogels (a COO- group of the carboxylic acid which easily absorb water).

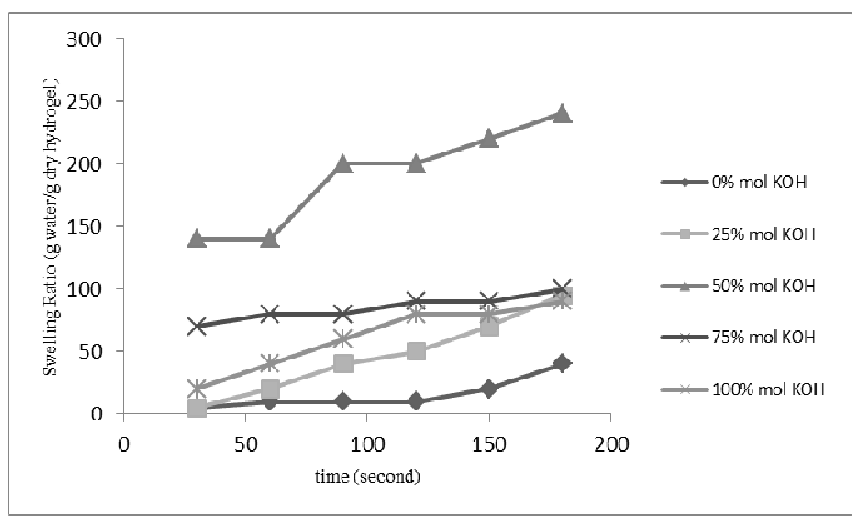

Fig. 5 Effect of time immersing to the swelling ratio of polymer with the variation of neutralization

At this stage, there is an interaction between the polymer with water molecules. Hydrogel swelling ratio at $50 \%$ acrylic acid neutralizing has a swelling ratio of $240 \mathrm{~g} / \mathrm{g}$ after $180 \mathrm{~s}$ time of immersion. It is the best value compared to the others because of the presence of ions $\mathrm{COO}$ in the network causes the distance between the matrix becomes wide which allows hydrogel to absorb more water. But the neutralization above $75 \%$ causes the value of swelling water decreases due to growing number of $\mathrm{K}+$ ions contained in the network that will interact with the $\mathrm{COO}$ group, thereby reduce the repulsive force between the group refused $\mathrm{COO}$, as a consequent the distance between the fixed network and the ability to swell decreases.

The smaller concentration of urea and $\mathrm{NaCl}$ resulted in higher hydrogel swelling ratio (Fig 6). The highest value of swelling reached in this study are $750 \mathrm{~g} / \mathrm{g}$ for urea and 378 $\mathrm{g} / \mathrm{g}$ for $\mathrm{NaCl}$. 


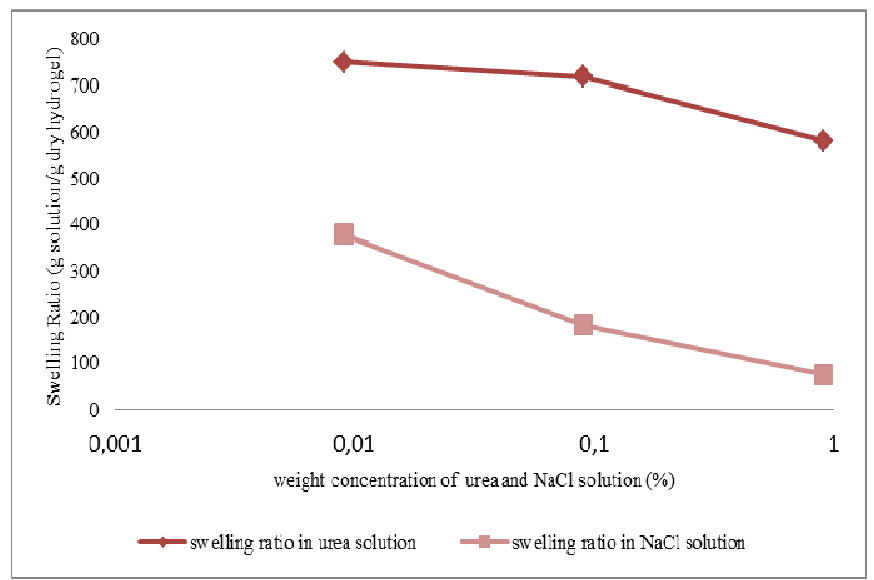

Fig. 6 Swelling behavior of hydrogel in the salt and urea solution

\section{Gel Content Analysis}

In Fig. 7 presents the influence of acrylic acid neutralization to the gel obtained by gamma irradiation. From Fig. 7 shows that neutralization of $50 \%$ resulted in relatively high gel content reached up to $96.34 \%$, and the increasing of neutralization degree causes the decreasing of gel content of up to $6 \%$, which the gel content of $100 \%$ neutralization is $91.23 \%$. This may be due to the formation of a homopolymer or a water-soluble peroxide. In addition, it can also be caused by the degradation of chitosan or acrylic acid during the irradiation process.

\section{E. EDS Study}

EDS of a hydrogel is an important parameter which indicates the ratio of swelling in the maximum condition of swelling within a certain period. The maximum swelling condition occurs as a result of hydrophilic group bonds with water, and there is an attraction in the superabsorbent network in a state of equilibrium. In general, each superabsorbent hydrogel has a particular EDS value depends on the components inside. Therefore, the applications are relatively wide for superabsorbent hydrogel [21].

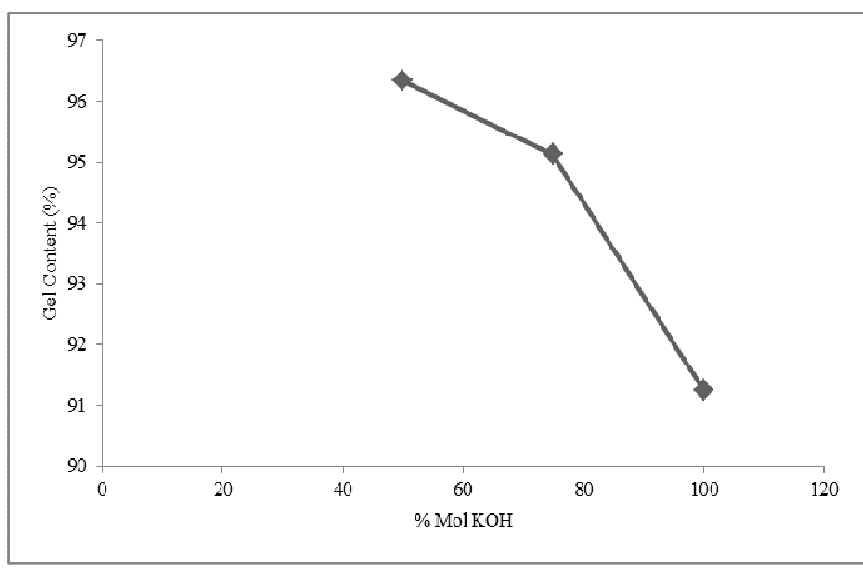

Fig. 7 Effect of mol concentration of $\mathrm{KOH}$ used for neutralization to the gel content

In Fig. 8 presents the influence of mol concentration of $\mathrm{KOH}$ used for acrylic acid neutralization at a constant $5 \mathrm{kGy}$ of irradiation to the EDS which were measured for 24 hours of immersion in distilled water at room temperature. It can be seen that the equilibrium swelling ratio of hydrogels increased during the increasing of mol concentration of $\mathrm{KOH}$ for neutralization in the range of $0 \%$ to $75 \%$. It is indicated that the prepared homopolymer hydrogels with $0 \%$ and $100 \%$ of $\mathrm{KOH}$ resulted in a small amount of crosslinked hydrogel network. As a result, the hydrogel products can only absorb and retain small quantities of water [31].

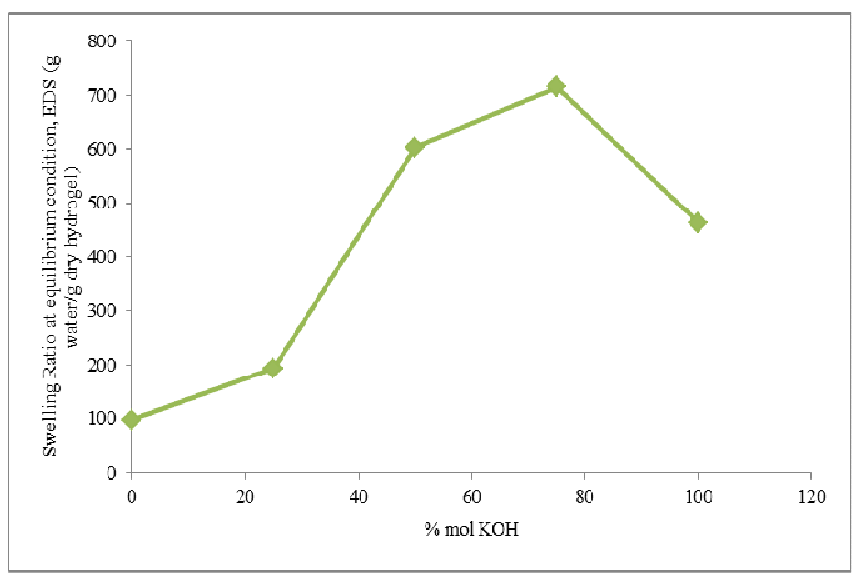

Fig. 8 Effect of neutralization to swelling ratio after 24 hour

When the hydrogels synthesize from partially neutralized of acrylic acid irradiated together with chitosan dissolved in water, the carboxyl anions were exposed to water then the hydrogels rapidly swell. The optimum result of EDS obtained in this research was $715 \mathrm{~g}$ water/g dry hydrogel and reached the use of $75 \%$ mol concentration of $\mathrm{KOH}$.

\section{F. SEM Study}

SEM photos of hydrogels generally provide information on pore geometry and size in a specific location. Therefore, the SEM images provide relevant information related to homogeneity and heterogeneity of the hydrogel network [15].

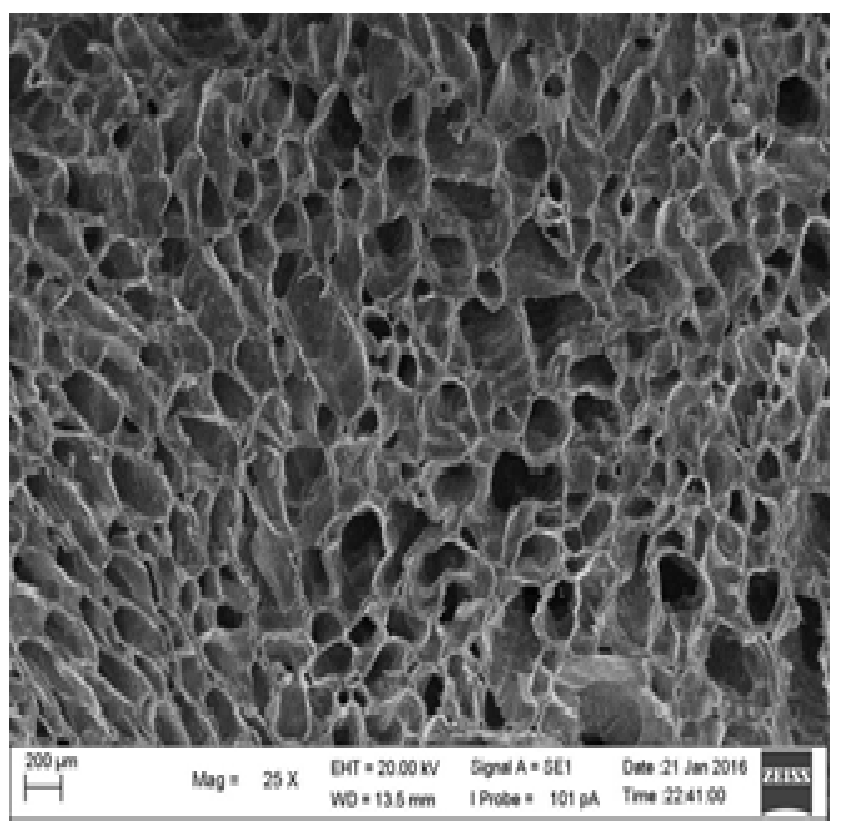

Fig. 9 Photomicrograph hydrogel poly (potassium acrylic-chitosan) with $75 \%$ mole concentration of $\mathrm{KOH}(25 \mathrm{x})$

For this purpose, the surface SEM images and the inside of the hydrogel poly (potassium acrylate-chitosan) with the 
neutralization by using of $75 \%$ mole of $\mathrm{KOH}$ are presented in Fig. 9, 10 and 11. It is seen that the hydrogel surface consists of large pores which allow more water to be absorbed. There is also a thick polymer skin appears which may be caused by the collapse of the pores in the surface during the freeze drying process. This study resulted in large pore diameter which was estimated at $274.8 \mu \mathrm{m}$.

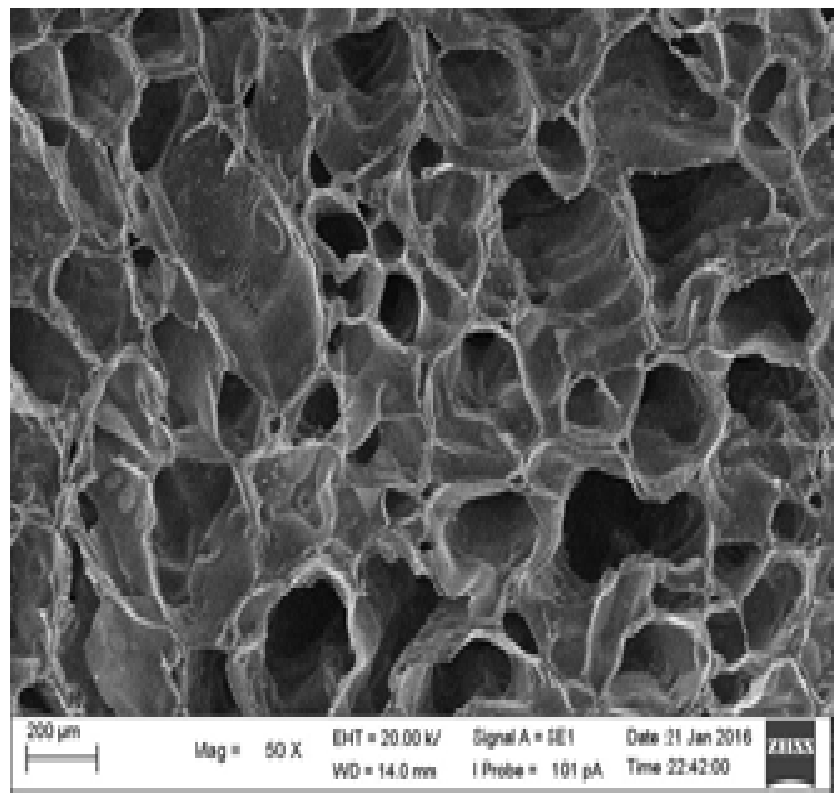

Fig.10 Photomicrograph hydrogel poly (potassium acrylic-chitosan) with $75 \%$ mole concentration of $\mathrm{KOH}(50 \mathrm{x})$

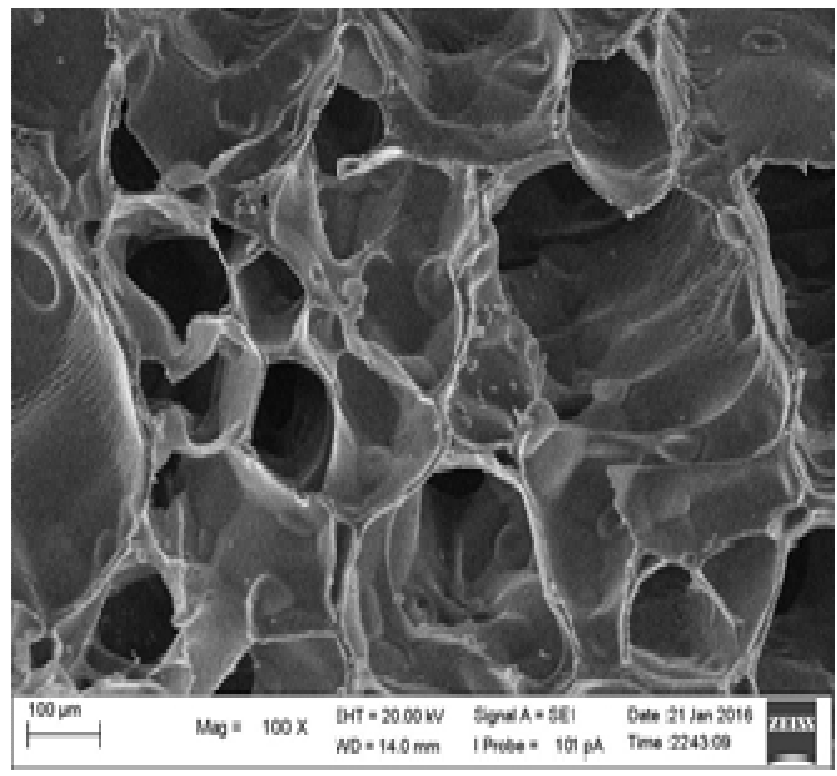

Fig. 11 Photomicrograph hydrogel poly (potassium acrylic-chitosan) with $75 \%$ mole concentration of $\mathrm{KOH}(75 \mathrm{x})$

\section{CONCLUSIONS}

Based on research that has been done, there are some things that can be inferred, the acrylic acid in partial neutralization with potassium hydroxide by the addition of chitosan as a natural material can be synthesized by gamma irradiation technique to produce poly (potassium acrylatechitosan) are crosslinked. The concentration of the acrylic acid neutralization optimum is $75 \mathrm{~mol} \% \mathrm{KOH}$ with $5 \mathrm{kGy}$ irradiation dose, and chitosan mass of 0.5 grams provide the maximum swelling value of $715 \mathrm{~g} / \mathrm{g}$ with a gel fraction value of $91.23 \%$. Effect of $\mathrm{NaCl}$ and urea concentrations affect the absorbency. The highest absorption capacity was obtained from $0.009 \%$ concentration of $750 \mathrm{~g} / \mathrm{g}$ of urea and $378.33 \mathrm{~g} / \mathrm{g}$ for $\mathrm{NaCl}$.

\section{ACKNOWLEDGMENT}

We would like to thank The Ministry of Research Technology and Higher Educational of Indonesia for the support through Hibah Bersaing grant.

\section{REFERENCES}

[1] N. A. Peppas and A. S. Hoffman, "Hydrogels", Biomaterials Science, $3^{\text {rd }}$ ed, 2013, 166-179.

[2] Y. Zheng and A. Wang, "Superadsorbent with three-dimensional networks: From bulk hydrogel to granular hydrogel", European Polymer Journal, 72, 2015, 661-686.

[3] C. Yang, L. Xu, Y. Zhou, X. Zhang, X. Huang, M. Wang, Y. Han, M. Zhai, S. Wei, J. Li, "A green fabrication approach of gelatin/ CMchitosan hybrid hydrogel for wound healing", Carbohydrate Polymers, 82, 2010, 1297-1305.

[4] N. Yusof, A.H.A. Hafiza, R.M. Zohdi, Md.Z.A. Bakar, "Development of honey hydrogel dressing for enhanced wound healing", Radiation Physics and Chemistry, 76, 2007, 1767-1770.

[5] S.Y. Ong, J. Wu, S.M. Moochhala, M.H. Tan, J. Lu, "Development of a chitosan-based wound dressing with improved hemostatic and antimicrobial properties", Biomaterials, 29, 2008, 4323-4332.

[6] T. Wang, X.K. Zhu, X.T. Xue, D.Y. Wu, "Hydrogel sheets of chitosan, honey and gelatin as burn wound dressing", Carbohydrate Polymers, 88, 2012, 75-83.

[7] M. Tamada, N. Seko, F. Yoshii, "Application of Radiation-Grafted Material for Metal Adsorbent and Crosslinked Natural Polymer for Healthcare Product", Radiation Physics and Chemistry, 71, 2004, 221-225.

[8] K. Kosemund, H. Schlatter, J.L. Ochsenhirt, E.L. Krause, D.L Marsman, G.N. Erasala, "Safety evaluation of superabsorbent baby diapers", Regulatory Toxicology and Pharmacology, 53, 2009, 81-89.

[9] K. Kabiri, H. Omidian, S. A. Hashemi, M. J. Zohuriaan Mehr, "Synthesis of fast swelling superabsorbent hydrogels: effect of crosslinker type and concentration on porosity and absorption rate", European Polymer Journal, 39, 2003, 1341-1348.

[10] M. Sadeghi, H. Hosseinzadeh, "Synthesis and Properties of Collageng-Poly(Sodium Acrylate-co-2-Hydroxyethylacrylate) Superabsorbent Hydrogels", Brazilian Journal of Chemical Engineering, 30 (02), 2013, 379-389.

[11] M. Likhitha, R. R. N. Sailaja, V. S. Priyambika, M. V. Ravibabu, "Microwave assisted synthesis of guar gum grafted sodiumacrylate/cloisite superabsorbent nanocomposites: Reaction parameters and swelling characteristics", International Journal of Biological Macromolecules, 65, 2014, 500-508.

[12] N. Peng, Y. Wang, Q. Ye, L. Liang, Y. An, Q. Li, C. Chang, "Biocompatible cellulose-based superabsorbent hydrogels with antimicrobial activity", Carbohydrate Polymers, 137, 2016, 59-64.

[13] C. Spagnol, F. H. A. Rodrigues, A. G. B. P. Pereira, A. R. Fajardo, A. F. Rubira, E. C. Muniz, "Superabsorbent hydrogel nanocomposites based on starch-g-poly(sodium acrylate) matrix filled with cellulose nanowhiskers", Cellulose, 19 (4), 2012, 1225-1237.

[14] C.K.S. Pillai, W. Paul, C.P. Sharma, "Chitin and chitosan polymers: chemistry, solubility and fiber formation", Progress in Polymer Science, 34, 2009, 641-678.

[15] G.A. Morris, J. Castile, A. Smith, G.G. Adams, S.E. Harding, "The kinetics of chitosan depolymerisation at different temperatures", Polymer Degradation and Stability, 94, 2009, 1344-1348.

[16] H. H. Sokker, A. M. Abdel Ghaffar, Y. H. Gad, A. S. Aly, "Synthesis and characterization of hydrogels based on grafted chitosan for the controlled drug release", Carbohydrate Polymers, 75, 2009, 222-229.

[17] C. Yu and T. Hui-min, "Crosslinked carboxymethylchitosan-gpoly(acrylic acid) copolymer as a novel superabsorbent polymer", Carbohydrate Research, 341, 2006, 887-896.

[18] R.A.A. Muzzarelli, "Genipin-crosslinked chitosan hydrogels as 
biomedical and pharmaceutical aids", Carbohydrate Polymers, 77, 2009, 1-9.

[19] N. Nagahama, H. Maeda, T. Kashiki, R. Jayakumar, T. Furuike, H. Tamura, "Preparation and characterization of novel chitosan/gelatin membranes using chitosan hydrogel", Carbohydrate Polymers, 76, 2009, 255-260

[20] Y.F. Tang, Y.M. Du, X.W. Hu, X.W. Shi, J.F. Kennedy, "Rheological characterization of a novel thermosensitive chitosan/poly(vinyl alcohol) blend hydrogel", Carbohydrate Polymers, 67, 2007, 491-499.

[21] H. Tanuma, T. Saito, K. Nishikawa, T. Dong, K. Yazawa, Y. Inoue, "Preparation and characterization of PEG-cross-linked chitosan hydrogel films with controllable swelling and enzymatic degradation behavior", Carbohydrate Polymers, 80, 2010, 260-265.

[22] J.A.G. Barros, A.J.C. Brant, L.H. Catalani, "Hydrogels from chitosan and a novel copolymer Poly (N-vinyl-2-pyrolidone-co-acrolein)", Materials Sciences and Application, 2, 2011, 1058-1069.

[23] A.S.G. Magalhães, M.P.A. Neto, M.N. Bezerra, N.M.P.S. Ricardo, J.P.A. Feitosa, "Application of FTIR in the determination of acrylate content in poly (sodium acrylate-co-acrylamide) superabsorbent hydrogels", Quim. Nova, 35 (7), 2012, 1464-1467.

[24] D.R. Barleany, F. Ulfiyani, S. Istiqomah, H. Heriyanto, Rahmayetty, Erizal, "Swelling properties of Cassava starch grafted with Poly (potassium acrylate-co-acrylamide) superabsorbent prepared by ionizing radiation", AIP Proceeding, December 2015.

[25] Erizal, "Synthesis of poly (acrylamide-co-acrylic acid)- starch based superabsorbent hydrogels by gamma radiation: Study its swelling behavior", Indo. J. Chem, 12 (2), 2012, 113-118.

[26] G. Huacai, P. Wan, L. Dengke, "Graft Copolymerization of Chitosan with Acrylic Acid under Microwave Irradiation and its Water Absorbency", Carbohydrate Polymers, 3, 2006, 372-378.
[27] C. Spagnol, F.H.A. Rodrigues, A.G.B. Pereira, P.A.R. Fajardo, "Super absorbent Hydrogel Composite Made of Cellulose Nanofibrils and Chitosan-grafted- Poly (Acrylic Acid)", Carbohydrate Polymers, 87, 2012, 2038-2045.

[28] J. Liu, Q. Wang, A. Wang, "Synthesis and Characterization of Chitosan-g-Poly (Acrylic Acid)/Sodium Humate Superabsorbent", Carbohydrate Polymers, 70, 2007, 166-173.

[29] H. Ge, S. Wang, "Thermal Preparation of Chitosan-Acrylic Acid Superabsorbent: Optimization, Characteristic, and Water Absorbency", Carbohydrate Polymers, 113, 2014, 296-303.

[30] D. M. Soler, Y. Rodríguez, H. Correa, A. Moreno, L. Carrizales, "Pilot scale-up and shelf stability of hydrogel wound dressings obtained by gamma radiation, Radiation Physics and Chemistry, 81, 2012, 1249-1253.

[31] Erizal, B. Abbas, S.G. Sukaryo, D.R. Barleany, "Synthesis and characterization super absorbent hydrogels of partially neutralized acrylic acid prepared using Gamma irradiation; swelling and thermal behavior", Indonesian Journal of Chemistry, 15 (03), 2015, 281-287

[32] F. Kazemi, Z. Mohamadnia, B. Kaboudin, H. Gharibi, E. Ahmadinejad, Z. Taran, "Synthesis, characterization and swelling behavior investigation of hydrogel based on Aam and AA using CdSnanorods as photocatalyst initiator under different irradiations", Journal of Photochemistry and Photobiology A: Chemistry, 330, 2016, 102-109.

[33] S. Zhang, W. Wang, H. Wang, W. Qi, L. Yue, Q. Ye, "Synthesis and characterisation of starch grafted superabsorbent via $10 \mathrm{MeV}$ electron-beam irradiation", Carbohydrate Polymers, 101, 2014, 798803.

[34] webspectra.chem.ucla.edu//irtable.html 